\title{
HISTÓRIA DOS PROJETOS DE CONSERVAÇÃO DE ESPÉCIES DA FAUNA NO BRASIL
}

\section{HISTORY OF WILDLIFE CONSERVATION PROJECTS IN BRAZIL}

\author{
Fernanda Cornils Monteiro Benevides* \\ cornils.fernanda@hotmail.com \\ José Luiz de Andrade Franco** \\ jldafranco@terra.com.br \\ Vivian da Silva Braz ${ }^{* * *}$ \\ vsbraz@gmail.com
}

RESUMO: Este artigo traça uma história dos projetos de conservação de espécies da fauna no Brasil: projetos pioneiros iniciados pela Fundação Brasileira para a Conservação da Natureza (FBCN), entre 1966 e 1972; consolidação e surgimento de novos projetos de 1973 a 1988; e crescimento do número de projetos, de 1989 até o presente. Trata da cooperação da FBCN com o Instituto Brasileiro de Desenvolvimento Florestal (IBDF), com a Secretaria Especial de Meio Ambiente (SEMA) e com organizações não governamentais (ONGs) internacionais para o desenvolvimento dos projetos de conservação da fauna. A conclusão mostra a importância dos projetos de conservação da fauna para o desenvolvimento de uma consciência ampla sobre a perda da biodiversidade.

PALAVRAS-CHAVE: Projetos de conservação de espécies no Brasil, cooperação internacional, ONGs, ambientalistas, FBCN.

ABSTRACT: This article provides a brief history of fauna conservation projects in Brazil: pioneering projects initiated by the Brazilian Foundation for the Conservation of Nature (FBCN) between 1966 and 1972; consolidation and emergence of new projects from 1972 to 1988, significant growth the number of wildlife conservation projects from 1989 to the present. Demonstrates the FBCN cooperation with the Brazilian Institute for Forestry Development (IBDF), the Special Secretariat for the Environment (SEMA), and international nongovernmental organizations (NGOs) for the development of projects of wildlife conservation. The conclusion shows the importance of wildlife conservation projects in Brazil to develop a broad awareness of the issue of biodiversity loss.

KEYWORDS: Species conservation projects in Brazil, international cooperation, NGOs, environmentalists.

\section{Introdução}

O presente artigo enfoca: a) o surgimento dos primeiros projetos de conservação de espécies da fauna no Brasil, empreendidos pela Fundação Brasileira para a Conservação da Natureza (FBCN), de 1966 a 1972; b) a consolidação destes projetos pioneiros e o surgimento de novos projetos, desenvolvidos pela $\mathrm{FBCN}$ em parceria com o Instituto Brasileiro de Desenvolvimento Florestal (IBDF), com a Secretaria Especial de Meio Ambiente (SEMA), e com

\footnotetext{
* Doutora em Desenvolvimento Sustentável pelo Centro de Desenvolvimento Sustentável da Universidade de Brasília CDS-UnB e membro do Observatório das Unidades de Conservação e Políticas Sociais Conexas. Professora do Centro Universitário de Brasília

**Doutor em História pela Universidade de Brasília. Pós-Doutor em Desenvolvimento Sustentável pelo Centro de Desenvolvimento Sustentável da Universidade de Brasília. Professor da Universidade de Brasília e do Centro de Desenvolvimento Sustentável da Universidade de Brasília. Bolsista de Produtividade em Pesquisa do CNPq - Nível 2.

*** Doutora em Ecologia pela Universidade de Brasília. Professora no Centro Universitário de Anápolis/ UniEVANGÉLICA.Tem experiência na área de Ecologia, com ênfase em Conservação da Biodiversidade.
} 
a cooperação de instituições internacionais como a "International Union for Conservation of Nature" (IUCN), o "World Wide Fund for Nature" (WWF), "Conservation International" (CI) e a "The Nature Conservancy" (TNC); de 1972 a 1989; e c) o expressivo crescimento do número de projetos de conservação de espécies da fauna, relacionados com o aparecimento de novas organizações não governamentais (ONGs) nacionais dedicadas à conservação da natureza e o estabelecimento de grandes ONGs internacionais - WWF, Cl e TNC - no Brasil, de 1989 até o presente.

As principais fontes de pesquisa foram publicações das organizações responsáveis pelos projetos de conservação de espécies da fauna no Brasil, depoimentos de pesquisadores e participantes desses projetos e bibliografia produzida sobre o assunto.

\section{Início das preocupações com a conservação da fauna}

A extinção de espécies da fauna pelos humanos (Homo sapiens) não é um evento recente na história. À medida que os humanos colonizaram continentes e ilhas, desde a préhistória, a pressão de caça sobre espécies da megafauna levou muitas delas ao desaparecimento (DEAN, 1996; DIAMOND 1997; FERNANDEZ et al., 2012). As preocupações com a rarefação e com a proteção da fauna silvestre, por conseguinte, estiveram presentes em várias sociedades e em diversos momentos. Eram associadas a valores instrumentais, relacionados a interesses humanos (CHAN et al., 2016) como a conservação de um recurso útil, ou a motivos de ordem ética, estética ou religiosa, em geral associados ao estabelecimento de tabus que impediam a caça de determinadas espécies consideradas sagradas.

Na Ásia, por volta do ano 252 a.C., o imperador hindu Asoka decretou proteção aos peixes, aos animais terrestres e às florestas. Kublai Khan (1215-1294), soberano da Mongólia, decretou proibida a caça de aves e mamíferos nos períodos de reprodução. Na Europa Oriental, durante o fim do século XIII, a caça do auroque (Bos primigenius) foi proibida nas terras do duque Boleslau da Mazóvia. No século XVI, os auroques já eram tão raros que o rei Sigismundo III criou reservas nas áreas onde se encontravam os últimos espécimes, o que não impediu a extinção da espécie em 1627, quando o último indivíduo de que se tem registro morreu na floresta de Jaktorowka, na Polônia. Durante a Idade Média e a Idade Moderna, a proteção da fauna na Europa foi instituída por leis que garantiam o monopólio da caça para a nobreza. No continente Africano, as iniciativas legais para conter a exploração da fauna 
tiveram início em 1658, quando foram estabelecidas leis de restrição ao abate de pinguins, focas e elefantes. Foi a partir da segunda metade do século XIX, no entanto, que as preocupações com a preservação de espécies e com a criação de áreas destinadas à proteção da vida selvagem começaram a ser mais frequentes (DORST, 1973; MCCORMICK, 1992; NASH, 2001; VUURE, 2012; HOLDGATE, 2014).

Em 1824 foi fundada a "Society for the Protection of Animals", e em 1870 essa instituição realizou uma campanha contra crueldade aos animais. De uma forma geral os pássaros foram os animais que tiveram mais iniciativas voltadas para a sua preservação, e as ações para proteção desse grupo remontam a 1845, quando o Dr. Edward Baldamus (18121893) propôs a proteção dos animais, em particular as aves, na primeira assembleia da “ German Ornithological Society" Foram eles que inspiraram o primeiro organismo mundial voltado para a preservação da vida selvagem: a "East Riding Association for the Protection of the Sea Birds", fundada em 1867, na Inglaterra, com o objetivo de diminuir a matança de gaivotas. Graças a sua atuação, foi proclamado o "Sea Birds Preservation Act", que proibia a caça, durante o período reprodutivo, de 35 espécies (MCCORMICK, 1992; HOLDGATE, 2014).

As penas e as plumas das aves eram amplamente utilizadas em acessórios femininos na Grã-Bretanha no século XIX. Um grupo de mulheres, contudo, ao perceber os maus tratos sofridos pelos animais, se mobilizou, e entre 1869 e 1880 quatro leis do parlamento britânico tratavam da proteção de espécies de pássaros (MCCORMICK, 1992). A legislação que restringia a caça no território da Grã-Bretanha acabou por aumentar a demanda por plumagens e penas de espécies tropicais. Entre 1901 e 1905, foram vendidas para os Estados Unidos da América (EUA), Alemanha, Inglaterra e França cerca de seis mil quilos de penas de origem brasileira (DUARTE, 2013).

A primeira organização com o objetivo de proteger os grandes mamíferos foi fundada em 1903 no continente africano: a "Society for the Preservation of the Wild Fauna of the Empire", atualmente conhecida como "Fauna and Flora Preservation Society". Composta por um grupo de naturalistas britânicos e estadistas norte-americanos, teve como fruto de seus esforços o controle das atividades de caça em grandes regiões do Leste e do Sul da África. Influenciou também na criação do "Kruger National Park" e do "Serengeti National Park". A sociedade de História Natural de "New South Walesna" na Tasmânia, também em 1903, concentrava seus esforços na preservação de marsupiais. 
Os EUA, entre 1916 e 1940, promoveram a assinatura de uma série de acordos internacionais para a proteção da fauna: o primeiro com a Grã-Bretanha; o segundo com o México e o Canadá, com o objetivo de proteger as aves migratórias; e o terceiro, a Convenção sobre a Proteção da Natureza e a Preservação da Vida Selvagem, também conhecida como Convenção do Hemisfério Ocidental, foi aberto à assinatura de todos os países americanos. A caça da águia (Haliaeetus leucocephalus) foi proibida nos EUA em 1918. Ainda assim, ela foi quase extinta nos anos 1940 devido ao uso de DDT, tendo sido salva graças a estratégias conservacionistas que impediram a continuidade do uso do agrotóxico. Outras espécies não tiveram a mesma sorte: o pombo migrador (Ectopistes migratorius) e o periquito-da-carolina (Conuropsis carolinensis), que foram extintos em 1914 (DORST, 1973; MCCORMICK, 1992; QUAMMEN, 2008).

O dodô, um pombo pesado e incapaz de voar que habitava as ilhas Maurício, se tornou um dos principais ícones da extinção por ação antrópica. Foi exterminado em 1662 e marca o início das extinções causadas desde a expansão marítima europeia (QUAMMEN, 2008). Os impactos dos humanos sobre a biodiversidade (não só sobre a fauna, mas sobre todos os seres vivos), sobretudo a partir da revolução industrial, resultaram em uma taxa de extinção de espécies que está hoje de 100 a 1000 vezes acima do que seria o normal (no processo evolutivo espécies desaparecem e surgem ao longo do tempo). Isto configura, para os cientistas dedicados à biologia da conservação, uma crise global da biodiversidade, como a que extinguiu os dinossauros há 65 milhões de anos atrás. As principais causas da perda de biodiversidade são destruição de habitats, espécies invasoras, poluição e exploração excessiva (caça, pesca e coleta). A destruição de habitats é, atualmente, a principal causa para o desaparecimento de espécies. Por isso, a relação forte entre a conservação de espécies e a criação de áreas protegidas (WILSON, 1994; PRIMACK et al, 2005; MAYR, 2005; GROMM et al. 2006).

A fauna, principalmente de mamíferos e de pássaros carismáticos, tem atraído a atenção para a questão mais ampla da perda de biodiversidade. Assim como em outras partes do mundo, as iniciativas de conservação de espécies no Brasil se deram a partir de iniciativas individuais e de grupos preocupados com a proteção da natureza. A partir da década de 1960, os projetos de conservação de espécies da fauna surgiram, se consolidaram, incorporaram novos elementos e se tornaram projetos de sucesso nacional e internacional. Os primeiros 
projetos brasileiros foram destinados a duas espécies de primatas: o mico-leão-dourado e o muriqui.

\section{A FBCN e os projetos pioneiros de conservação de espécies da fauna no Brasil: micos- leões-dourados, muriqui, muçuan e avoantes (1966 a 1972).}

O padre Antônio Pigafetta, em 1519, descreveu os micos-leões como: "lindos gatos próximos a micos e similares a leões" (KLEIMAN e RYLANDS, 2008). Esse é o primeiro relato sobre o Leontopithecus na natureza. O Príncipe Maximilian de Wied-Neuwied, naturalista alemão que esteve no Brasil no início do século XIX, em um misto de encantamento e espanto, referiu-se ao mico-leão como "interessante exemplar" (WIED-NEUWIED, 1940). Johann Natterer, naturalista austríaco, também viajante do século XIX, também fez menção à espécie (CORREA, 2006). Para esses naturalistas-viajantes, os primatas apareciam como abundantes, realidade que já não encontrou o primatólogo Adelmar Coimbra-Filho em meados do século XX (KLEIMAN e RYLANDS, 2008).

A primeira vez que Coimbra-Filho viu um mico-leão foi em 1940, quando ele estava com 16 anos: "estava amarradinho, era de uma família portuguesa... O bicho era tão extraordinário, me chamou tanto a atenção que não esqueci mais e quando vi um em liberdade, em 1942, numa saída pelo mato, decidi estudá-lo." (URBAN, 1998). Naquela época, não se conhecia sobre o primata muito mais do que o seu nome científico.

Coimbra-Filho é reconhecido como o primatologista brasileiro que salvou da extinção três espécies de micos: mico-leão-dourado (L. rosalia); mico-leão-preto (L. chrysopygus); mico-leão-da-cara-dourada (L. chrysomelas). Pioneiro da conservação de espécies da fauna do Brasil, ele fez o seu trabalho ir além. "Se no século XXI ainda voam tucanos numa Gávea cada vez mais populosa, é porque ele os soltou nos arredores lá vão mais de 30 anos, retomando o Parque Nacional da Tijuca para a Fauna nativa" (CORREA, 2006). Como primatólogo, ganhou fama internacional, o que Ihe rendeu ser homenageado com o nome científico de dois animais: um sauá nordestino, descoberto pelos pesquisadores Alfredo Laungguth e Shuji Kobayashi nas matas de Sergipe, batizado como Callicebus coimbrai, e um percevejo encontrado pelo entomólogo José Cândido Melo Carvalho, o Tadia coimbrai. Russell Mittermeier, renomado primatologista norte-americano, que realizou os seus primeiros estudos de primatas no Brasil, entre 1970 e 1980, considera o projeto de conservação dos micos-leões entre os que obtiveram maior sucesso na história da conservação mundial 
(KLEIMAN, 2008). "Como o panda-gigante na China, o orangotango e o rinoceronte-dasumatra na Indonesia e os lêmures no Madagascar, os micos-leões têm sido embaixadores internacionais para sua floresta" (CORREA, 2006).

Coimbra-Filho alertou que as populações de micos-leões-dourados estavam decaindo devido à exportação ilegal. Os primatas eram atrações ilustres e figuravam em museus e zoológicos ao redor do mundo. Em 1972, durante o histórico encontro internacional de primatologia, organizado pelo Zoológico de Washington, onde se debateu o "status" dos micos-leões-dourados em cativeiro, Coimbra-Filho conseguiu que os espécimes retornassem para o Brasil (KLEIMAN e RYLANDS, 2008)1: "Vários dos nossos micos são brasileiros naturalizados" (CORREA, 2006). Isso permitiu o repovoamento da Mata Atlântica com os micos-leões-dourados e evitou que o conhecimento atual da espécie se restringisse a gravuras e fotografias como no caso de outros animais extintos.

A perda de habitats, consequência do crescimento urbano, era o principal problema a ser enfrentado. Coimbra-Filho e Alceo Magnanini, engenheiro agrônomo e fitogeógrafo, na época funcionário do Serviço Florestal do Ministério da Agricultura, foram os primeiros a criar o primata em cativeiro, em 1962, com o objetivo de repovoar a Reserva Biológica de Jacarepaguá (URBAN, 1998). Devido à expansão imobiliária do Rio de Janeiro, a reserva nunca foi criada. O trabalho dos dois, no entanto, foi essencial para a delimitação de outra reserva que seria o lar definitivo para os micos-leões-dourados, a Reserva Biológica de Poço das Antas: "sem isso não ia ter reserva nem Mico-leão-dourado" (CORREA, 2006).

O muriqui é o maior primata das Américas, classificado em duas espécies com características ligeiramente distintas: o muriqui do norte (Brachyteles hypoxanthus) e o muriqui do sul (Brachyteles arachnoides), sendo a cor da cara dos adultos a diferença mais perceptível (MENDES et al. 2010). Ambos constam na lista da fauna brasileira ameaçada de extinção (MMA, 2014) como "criticamente em perigo", e "em perigo", respectivamente. Os muriquis têm características singulares que atraem pesquisadores de várias partes do mundo, sobretudo "os elevados níveis de tolerância que demonstram uns com os outros, o que define sua sociedade pacífica e igualitária e os distingue de todos os outros primatas" (CANDISANI, 2004).

\footnotetext{
${ }^{1}$ KLEIMAN, Devra G.; RYLANDS, Anthony B. (Editores) Micos Leões: biologia e conservação. Brasília: MMA. 2008.op.cit.
} 
Os primeiros projetos destinados para a conservação do mico-leão-dourado e do muriqui foram coordenados pela FBCN. Ela foi fundada em 1958 e durante muitos anos foi a principal gestora dos projetos de conservação de espécies da fauna no Brasil. No texto "Conceitos de Conservação", disponível no primeiro boletim da instituição, de 1966, fica claro o objetivo de unir uso racional dos recursos naturais com proteção da natureza: "Proteger não é o oposto de usar? Decididamente e definitivamente NÃO!" (MAGNANINI, 1966).

Apesar de o período inicial das atividades da FBCN, entre 1958 e 1966, ser considerado de dormência (FRANCO, 2013), a influência que alguns de seus membros exerciam sobre as esferas governamentais foi importante para a criação de 11 parques nacionais (Aparados da Serra, Araguaia, Ubajara, Brasília, Caparaó, Chapada dos Veadeiros, Emas, Monte Pascoal, São Joaquim, Sete Cidades e Tijuca) e uma floresta nacional (Caxiuanã), que garantiam o habitat de espécies ameaçadas, além da elaboração do anteprojeto de Lei que resultou no código florestal de 1965.

Nesse mesmo ano, foram criadas, no âmbito da FBCN, a "Comissão Técnica de Espécies Raras ou Ameaçadas de Extinção", coordenada por Fernando de Ávila Pires, e a "Comissão Técnica de Parques Nacionais e Reservas afins" coordenada por Harold Edgard Strang. Os objetivos das comissões eram a criação de áreas protegidas, a preservação de espécies raras ou ameaçadas de extinção e a cooperação entre governos e entidades internacionais interessadas na conservação dos recursos naturais. Tratava-se de: “experimentar, adaptativamente, no Brasil a divisão funcional da IUCN” (FBCN, 1966).

Os dois primeiros projetos de conservação de espécies da fauna no Brasil foram oficializados em 1967, e visavam os micos-leões-dourados e o Muriqui (FBCN, 1967). Os projetos contavam com o apoio do Programa Biológico Internacional, o que iniciou a cooperação entre a FBCN e o IUCN. Coimbra-Filho assumiu o projeto de conservação do mico e o zoólogo Álvaro Aguirre o do muriqui (MAGNANINI e COIMBRA-FILHO, 1967). Os objetivos dos dois projetos eram:

[...] conhecer a distribuição geográfica da espécie, no presente e no passado, principais populações e números de indivíduos, ciclo biológico, etologia, relações com outros animais e com o homem. Espera-se que ao terminar a pesquisa seja proposta e estabelecida uma reserva para a sobrevivência da espécie, caso não seja encontrada nas reservas já citadas por lei (FBCN, 1967). 
Uma importante conquista para a preservação de espécies da fauna foi a Lei de proteção à Fauna (Lei 5197, de 03 de Janeiro de 1967). Aprovada após o código florestal de 1965, contou com a participação ativa de membros da FBCN, entre os quais Fernando de Ávila Pires, José Cândido de Melo Carvalho e Maria Tereza Jorge Pádua.

Uma das mudanças mais significativas trazida pela nova lei foi dar ao Estado a tutela dos animais silvestres, além de proibir as atividades econômicas que impulsionavam um mercado tradicionalmente promissor de plumas, penas, peles e couros para uma elite ávida por consumo e desejosa de sofisticação (DUARTE, 2014).

A primeira lista de animais e plantas ameaçados de extinção foi elaborada em 1968, com base nos critérios de raridade, ameaça de extinção e perseguição pelo homem. A lista abrangia 19 mamíferos, 24 aves, 2 répteis e 13 plantas. Logo depois foi transformada em portaria pelo IBDF (Edital n 303/20 de Maio de 1968). Essa lista deu proteção integral ao muriqui e ao mico-leão-dourado, ao mico-leão-da-cara-dourada e ao mico-leão-preto. Nesse mesmo ano, teve início a colaboração entre o IBDF e a FBCN, a partir do Simpósio sobre Conservação da Natureza e Restauração do Ambiente Natural, organizado pela Academia Brasileira de Ciências, entre os dias 26 e 31 de Outubro. Essa colaboração foi decisiva para a consolidação da FBCN, pois a partir daí ela passou a contar com recursos para desenvolver projetos de conservação, entre eles os da fauna, além de aumentar a sua influência nas esferas governamentais.

A partir de 1969, outros dois projetos para a preservação de espécies da fauna foram iniciados pela FBCN: o do Muçuan (Kinosternon scorpiordes), uma espécie de tartaruga da região amazônica, utilizada na culinária, coordenado por Antenor Leitão; e o dos Ninhais da avoante (Zenaida auriculata noronha), ave intensamente caçada para o consumo humano, coordenado por Àlvaro Agirre (FBCN, 1970).

Com os projetos, as pesquisas sobre o comportamento e os hábitos alimentares dos primatas, quelônios e aves ganharam impulso. Coimbra-Filho e Magnanini, em 1967, fizeram algumas descobertas que seriam decisivas para a preservação dos primatas, como as de que os micos-leões-dourados usavam os ocos das árvores como local para dormir e que eram animais de hábitos diurnos (COIMBRA-FILHO e MITTERMEIER, 1977). Em 1968, foi criada a reserva para o mico-leão-dourado, localizada na bacia do Rio São João e na área de Poço das Antas no Rio de Janeiro. Em 1969, a região da reserva do UNA, no Sul da Bahia, foi proposta 
por Coimbra-Filho como lar definitivo dos micos-leões-da-cara-dourada. Nesse mesmo ano, a proibição de importação de micos-leões-da-cara-dourada foi solicitada pela União Internacional de Diretores de Jardins Zoológicos (IUDZG).

Durante uma excursão de campo em 1970 Coimbra-Filho redescobriu, na área do Parque Estadual do Morro do Diabo, uma espécie de mico-leão que era tida como extinta: o mico-leão-preto (Leontopithecus chrysopygus) (COIMBRA-FILHO, 1976). A FBCN, em parceria com o IBDF e com o Conselho Nacional de Pesquisas da Academia Brasileira de Ciências, organizou, em 1971, a "Reunião Técnica sobre Espécies Cinegéticas e Espécies Raras ou Ameaçadas de Extinção da Fauna Brasileira". As questões discutidas giraram em torno da situação dos animais de caça e da revisão da lista de animais ameaçados de extinção, publicada em 1968.

A FBCN declarou concluídos, em 1971, os projetos do muriqui e do mico-leãodourado, com a pesquisa da situação e as providências necessárias para sua sobrevivência encaminhadas para publicação. Nesse mesmo ano, Aguirre publicou um extenso trabalho sobre os muriquis, que foi editado pela Academia Brasileira de Ciências e que tratava de aspectos de taxonomia, distribuição geográfica, comportamento, ecologia e conservação do primata. O livro se tornou um clássico e serviu de base para as pesquisas subsequentes (MENDES et al., 2010). Paralelamente à publicação, Aguirre encontrava-se na pesquisa de campo do projeto das avoantes, estudando as aves em viagens por diferentes regiões do Brasil (FBCN, 1969).

Também em 1971, o WWF iniciou as suas atividades no Brasil em parceria com a FBCN. O primeiro projeto desenvolvido tinha como objetivo estudar o mico-leão-dourado e iniciou-se em virtude do conhecimento de Coimbra-Filho com John Perry, então presidente do "National Zoological Park" de Washington e membro do WWF, que se interessou pela conservação do mico-leão-dourado (FBCN, 1973). Ainda em 1971, foi instituída a Comissão de Imprensa, com financiamento do convênio com o IBDF. A partir da sua criação, a comissão foi influente na divulgação das atividades relacionadas com a conservação de espécies na grande mídia, o que fez a temática ganhar espaço entre vários setores da sociedade (FBCN, 1972).

A conferência "Salvando o Sagui Leão", realizada no "Smithsonian National Zoological Park" (SNZP), em 1972, foi patrocinada pelo "Wild Animal Propagation Trust" e contou com o apoio da "New York Zoological Society" (FBCN, 1973). Nela estiveram presentes 28 biólogos 
europeus, norte-americanos e brasileiros, que analisaram todos os dados disponíveis sobre os micos-leões e outros calitriquídeos (DUMOND, 1972). Essa conferência foi, ao mesmo tempo, ponto de chegada e de partida para a preservação dos micos. Chegada porque reuniu e sistematizou todo o conhecimento disponível sobre as espécies de mico, e partida porque as recomendações e indicações que saíram da conferência permitiram um programa mundial de manejo em cativeiro, com apoio da IUCN financiamento do WWF, o que permitiu a repatriação dos micos (BRIDGWATER, 1972).

Como desdobramento, foi elaborado um "studbook" sobre os primatas e um programa de manejo em cativeiro coordenado por Devra Kleiman. No Brasil, Coimbra-Filho estabeleceu colônias, ainda no ano de 1972, com apoio do Banco Biológico da Tijuca, patrocinado pela IUCN (com financiamento do WWF) e pelo governo brasileiro. O objetivo foi criar L. rosalia, L. chrysopygus e L. chrysomelas em cativeiro (COIMBRA-FILHO e MITTERMEIER, 1977).

A primeira Conferência Mundial sobre o Homem e o Meio Ambiente foi realizada pela Organização das Nações Unidas (ONU), em 1972, em Estocolmo, na Suécia. Tratava-se, sobretudo, de discutir a noção de finitude dos recursos naturais e o consequente manejo deles para a garantia da vida humana no planeta Terra. Muito do debate foi orientado por obras como o artigo "The Tragedy of the Commons", de Garrett Hardin, publicado em 1968 na revista científica "Science" e o livro "The Population Bomb", de Paul Ehrlich, publicado também em 1968, pela editora da Universidade de Stanford. As obras alertavam para o fato de um planeta finito não poder sustentar uma população crescente e com demandas ilimitadas. A partir da conferencia, os debates em torno da extinção de espécies e da diversidade da vida foram ganhando amplitude e mais espaço na sociedade.

A XI Assembleia Geral da UICN em Banff, no Canadá, também ocorreu em 1972. Paulo Nogueira Neto, na época membro do conselho deliberativo da $\mathrm{FBCN}$, compareceu como representante brasileiro. Lá conheceu Maurice Strong "chefe da nova organização da Organização das Nações Unidas que vai cuidar da defesa do meio-ambiente" (FBCN, 1973). Durante a Assembleia, Strong falou sobre a cooperação com a IUCN e o desejo de apoiar projetos já existentes em vários países, entre eles o Brasil.

Entre 1966 e 1972, surgiram os primeiros projetos de conservação da fauna no Brasil, todos eles no âmbito da FBCN (micos, muriqui, avoantes e muçuan). Durante o período, a 
FBCN se estruturou e ganhou espaços tanto nas esferas governamentais (IBDF, CNPQ) como nas não governamentais e internacionais (IUCN, WWF, SNZP, "National Zoological Park de Washington", "Wild Animal Propagation Trust"). Ela se tornou a ONG conservacionista mais importante do Brasil. A partir de 1972, com o ganho de visibilidade internacional dos projetos de conservação da fauna no Brasil e o consequente apoio técnico e financeiro, eles começaram a se multiplicar e a incluir novas demandas.

\section{Consolidação, crescimento e cooperação internacional nos projetos de conservação de espécies da fauna (1973 a 1989).}

A FBCN estabeleceu, em 1973, dois novos convênios na esfera governamental. O primeiro com a Secretaria de Ciência e Tecnologia da Guanabara, cujo objetivo era "desenvolver as atividades de informação e divulgá-las, relacionando-as ao meio ambiente e ao conservacionismo, visando à formação de uma mentalidade popular atualizada e construtiva nesse setor, primordial para o bem-estar da população."(FBCN, 1974). O segundo convênio foi estabelecido com a Secretaria Especial do Meio Ambiente (SEMA). A SEMA foi criada em resposta às pressões internacionais sofridas pelo Brasil durante a Conferência Mundial sobre o Homem e o Meio Ambiente. Paulo Nogueira Neto, o seu primeiro presidente, divulgou o objetivo prioritário do órgão: a criação de estações ecológicas. No III Congresso Internacional do WWF, realizado ainda em 1973, a FBCN ganhou uma medalha de ouro em reconhecimento ao seu trabalho para a conservação do patrimônio natural do Brasil e, particularmente, pela preservação da fauna brasileira. O prêmio foi recebido por José Candido de Melo Carvalho, primeiro cientista sul-americano a receber o prêmio internacional (FBCN, 1974).

Em dezembro de 1973, entrou em vigor no Brasil a Convenção Internacional para a Regulamentação da Pesca da Baleia (FBCN, 1974). No mesmo ano, Coimbra-Filho visitou a região do Una, na Bahia, a pedido do IBDF, para a escolha de um local destinado ao mico-leãoda-cara dourada. Simultaneamente, foi formada a primeira colônia em cativeiro de mico-leãopreto, a partir de sete indivíduos capturados por Coimbra-Filho no Morro do Diabo. O cativeiro foi estabelecido como parte do Banco Biológico da Tijuca (COIMBRA-FILHO, 1976).

A Reserva Biológica de Poço das Antas, no RJ, foi criada em 1974, totalizando uma área estimada em 3000 hectares. A reserva foi administrada pelo IBDF (FBCN, 1974). No ano seguinte, a reserva foi ampliada para 5000 hectares (Decreto no 76534 de 3 de novembro de 
1975). Em 1976, algumas terras foram compradas para o estabelecimento de uma reserva destinada ao mico-leão-da-cara-dourada. Russel Mittermeir coordenou o levantamento dos primatas entre 1979 e 1985, patrocinado pelo "WWF primate program" (MIITERMEIER e COIMBRA-FILHO, 2008). Como fruto da pesquisa, os dados e recomendações foram submetidos ao governo brasileiro em 1980, com o intuito de justificar a criação da reserva. Nesse mesmo ano, foi criada a Reserva Biológica do Una, administrada pelo IBDF.

Os muriquis encontravam-se em situação crítica devido à perda gradativa de habitats e à caça predatória (MENDES et al., 2010). Em 1976, uma população desses primatas foi encontrada em um remanescente florestal de 880 hectares, localizado na floresta da Fazenda Montes Claros, em Minas Gerais. A reserva existia graças ao proprietário, Feliciano Miguel Abdala, que não desmatou a região para o plantio de café. O Professor Akira Nishimura iniciou os primeiros estudos sistemáticos sobre os muriquis de Montes Claros em 1977. A partir de então, o WWF, por influência de Russel Mittermier, passou a destinar fundos para as pesquisas de longo prazo sobre o primata. A bióloga Karen Strier iniciou os seus estudos sobre o comportamento dos muriquis, que ela acompanha até hoje, em 1982 (Quammen, 2008; Candisani, 2004).

A engenheira agrônoma Maria Tereza Jorge Pádua assumiu a diretoria do Departamento de Parques Nacionais e Reservas Equivalentes do IBDF em 1979 e em 1980 coordenou, juntamente com José Cauêtê de Alburqueque e Guy Marcovaldi, o primeiro levantamento das espécies de tartarugas marinhas que ocorriam no litoral brasileiro e das suas áreas de desova. A partir disto, as primeiras ações para a preservação das tartarugas tiveram início. Em 1983, o Projeto Tamar monitorou a primeira temporada de reprodução das cinco espécies ocorrentes no Brasil (Chelonia mydas, Caretta caretta, Dermochelys coriacea, Eretmochelys imbricata e Lepidochelys olivacea), em três bases instaladas no litoral: praia de Santa Isabel, em Pirambu, Litoral Norte de Sergipe; Praia de Comboios, Litoral Norte do Espírito Santo; e Praia do Forte, no litoral Norte da Bahia. A FBCN recebia e gerenciava o financiamento destinado ao TAMAR além de contribuir com quadro de técnico (FUNDAÇÃO PRÓ-TAMAR, 2000; entrevista com Maria Tereza Jorge Pádua).

Entre as organizações de cooperação internacional para os projetos de conservação de espécies da fauna junto à FBCN, a mais influente foi a IUCN. Durante a primeira gestão de José Cândido de Mello Carvalho, zoólogo e entomologista do Museu Nacional do Rio de 
Janeiro e Universidade Federal do Rio de Janeiro, entre 1966 e 1969, a FBCN se estruturou e passou a funcionar nos moldes da IUCN, tendo como objetivos principais a preservação das espécies da fauna e da flora silvestre e a criação de áreas protegidas para a manutenção dos habitats das espécies ameaçadas de extinção. Carvalho teve uma segunda gestão, de 1978 a 1981. A FBCN também influenciou a IUCN. Isto é perceptível na ocupação paralela de cargos nas duas instituições por membros da FBCN, como foi o caso do próprio Carvalho, que foi membro do conselho da IUCN por dois mandatos (1963-1970 e 1976-1981), quando representou os países Sul Americanos não andinos. Paulo Nogueira Neto e Maria Tereza Jorge Pádua, ambos membros da FBCN, ocuparam essa mesma posição entre 1971 e 1975 e entre 1976 e 1981, respectivamente. Durante essa fase, considerada de apogeu, a FBCN contava com um quadro de cientistas e pessoal de apoio pagos, além de um corpo de voluntários (FRANCO e DRUMMOND, 2013).

Os membros da FBCN participaram de vários encontros e eventos que tratavam da cooperação internacional com o propósito de conservação de espécies: "Graças ao meu esforço e fruto de minhas atividades na IUCN, consegui que o conselho nacional de Pesquisas viesse a participar do Programa Biológico Internacional, sugerido pela Índia e praticamente comandado por europeus e americanos" (CARVALHO, 1988). A FBCN geria, também, os recursos do WWF no Brasil: "A ideia original era a mesma relação entre o WWF e a IUCN, ou seja, a FBCN receberia fundos do WWF e prestaria a essa organização os mesmos serviços que Ihe eram prestados pela IUCN em âmbito internacional"(FBCN, 1988).

No relatório das atividades realizadas entre 1987 e 1988, divulgado pelo Boletim FBCN , constava no item Atividades técnico-científicas uma série de projetos existentes decorrentes de convênios ou contratos. O Projeto Conservação das Tartarugas Marinhas visava apoiar o Projeto TAMAR, do IBDF, financiado pelo WWF, Petrobrás, Fundação Garcia D'Avila e Aracruz celulose. Na época, o TAMAR contava com pontos de desova em seis praias da costa brasileira: Comboios e Povoação (Espírito Santo), Interlagos e do Forte (Bahia), Pirambu ou Santa Isabel (Sergipe), Lençóis Maranhenses (Maranhão), em duas ilhas oceânicas (Fernando de Noronha e Trindade), além do Atol das Rocas. Durante a temporada de desova, eram desenvolvidos programas de educação ambiental (FBCN, 1988; FUNDAÇÃO PRÓTAMAR, 2000). 
O projeto Estudo Ecológico e Reintrodução do Mico-Leão-Dourado na Reserva Biológica de Poço das Antas, coordenado por Coimbra-Filho, era desenvolvido em parceria com o "Smithsoian Institution EE.UU", Centro de Primatas (FEEMA), IBDF, CPRJ, WWF-US. Após algumas tentativas fracassadas, em 1987, foram introduzidos 21 animais que se adaptaram ao habitat. O projeto Educação Conservacionista sobre Mico-Leão-Dourado, contava com o apoio do WWF-US, do "Friends of the Nature Zoo" e da Fundação Roberto Marinho, e buscava informar e educar a população sobre a importância da conservação dos micos, por meio de visitas guiadas à reserva de Poço das Antas. A mesma estratégia era seguida em outro projeto gerido pela FBCN: Muriquis na Fazenda Montes Claros: pesquisa, turismo e Educação Conservacionista (FBCN, 1988).

O projeto Aves Ameaçadas do Nordeste do Brasil, coordenado por Dante Luiz Martins Teixeira, Museu Nacional do Rio de Janeiro, pesquisou 400 aves da região com alto grau de endemismo. O Projeto Proteção da Arara-Lear (Lear's macaw), no raso da Catarina, localizado no nordeste da Bahia, foi realizado em parceria com a SEMA e o WWF. O projeto Pesquisa e Identificação da Baleia-Franca-Austral no Sul do Brasil ficou a cargo do biólogo José Truda Pallazzo Jr e foi desenvolvido com o apoio da Universidade Federal de Santa Catarina. O projeto Levantamento para verificar o estado atual e a biologia da Ararinha (Spix macaw) teve como responsável o Paul Roth, da Universidade Federal do Maranhão, e como financiador o WWF. Nesse período, a densidade da espécie já era considerada baixa e de difícil estudo. Depois de uma série de viagens ao Sul do Maranhão, Piauí, Pará e Bahia não foram encontrados espécimes significativos, por isso o projeto foi encerrado (FBCN, 1988).

A FBCN, entre 1973 e 1989, ganhou amplitude e representatividade como a principal ONG brasileira para a conservação de espécies da fauna e ampliou os projetos de conservação de espécies in-situ e ex-situ. As estratégias para a conservação da fauna estavam fortemente imbricadas com a criação e a gestão de áreas protegidas e com projetos de educação ambiental. O uso de uma espécie "guarda-chuva", isto é, uma espécie carismática que ao ter protegido o seu habitat, garantia a outras espécies da mesma área de ocorrência a mesma proteção foi bastante característico dos projetos desenvolvidos. Assim ocorreu com o peixeboi marinho, que "pegou carona" nas áreas de ocorrência das tartarugas do projeto Tamar (FUNDAÇÃO PRÓ-TAMAR, 2000). 
As atividades da FBCN eram divulgadas, desde 1966, pelo Boletim Informativo FBCN, publicado anualmente. O FBCN Informativo apareceu em 1977, era trimestral e contava com recursos do convênio com o IBDF. A partir de então, o Boletim Informativo FBCN passou a ser simplesmente Boletim FBCN (FRANCO e DRUMMOND, 2013). O FBCN Informativo, uma publicação mais expedita, pretendia ser:

[...] um canal de comunicação aberto a todos os que, preocupados com o uso correto dos nossos recursos naturais, com a implantação efetiva de nossos parques nacionais e reservas equivalentes, com a defesa de nossa fauna e de nossa flora, aliás a mais rica de um só País, tenham algo valioso a divulgar, como informação autêntica, categorizada e de interesse coletivo (FBCN, 1977).

A FBCN participou, também, da criação do primeiro programa de graduação de pesquisa em áreas selvagens, realizado na Universidade Federal de Minas Gerais. Além disso, ela foi o modelo para o estabelecimento de novas ONGs conservacionistas: a Biodiversitas, MG, e a Funatura, DF (FRANCO e DRIMMOND, 2013).

Durante os anos 1980, as preocupações com a extinção de espécies e o debate internacional em torno da preservação da diversidade da vida se intensificaram e tornaramse mais difundidos. A biologia da conservação se desenvolveu como um ramo importante da biologia, voltado para a produção e a aplicação de conhecimentos sobre a conservação de espécies, ecossistemas e pools genéticos. As discussões sobre como conciliar a presença humana - sobretudo de grupos sociais carentes e excluídos da maior parte dos benefícios gozados pelas sociedades de consumo afluente - e a conservação de espécies e ecossistemas também ganharam centralidade. Estes temas foram conquistando espaço crescente no âmbito da IUCN e se afirmaram como os principais focos de suas comissões e de seu Congresso Mundial de Parques Nacionais e Reservas Equivalentes, realizado desde 1962, a cada dez anos (MCCORMICK, 1992; GROOM et al.2006; QUAMMEN, 2008; FRANCO e SCHITINI, 2010).

Os projetos de conservação da fauna no Brasil não ficaram alijados dos debates internacionais. Os seus membros participavam deles e eram "up to date" com o conhecimento e as práticas relacionadas com a conservação. Novas demandas surgiram e os projetos de conservação da fauna tiveram que lidar com elas. Ao lado disso, o aparecimento de novas ONGs brasileiras e o estabelecimento no Brasil das grandes ONGs internacionais dedicadas à conservação da fauna configuraram um novo quadro, mais variado e mais complexo. 


\section{Novas propostas, crescimento expressivo dos projetos e situação dos projetos de conservação da fauna brasileira (de 1989 até o presente).}

A partir do final dos anos 1980 e do início dos anos 1990, os projetos de conservação dos micos-leões já haviam ganhado fama internacional, além de atraído pesquisadores de várias partes do mundo. Para os micos-leões foram criadas a Reserva Biológica de Poço das Antas (mico-leão-dourado - Leontopithecus rosalia); a Reserva Biológica de UNA (mico-leãoda-cara-dourada - Leontopithecus chrysomelas); o Parque Estadual do Morro do Diabo e a Estação Ecológica de Caetetus (mico-leão-preto - Leontopithecus chrysopygus); e o Parque Nacional do Superagui (mico-leão--da-cara-preta - Leontopithecus caissara - esta última espécie foi descrita apenas em 1990) (KLEIMAN e RYLANDS, 2008).

Os comitês internacionais para o manejo do mico-leão-preto, do mico-leão-da-caradourada e do mico-leão-dourado foram reconhecidos oficialmente pelo governo brasileiro em 1990 (Edital n 1203/ 18 julho de 1990; Edital no 1.204/18 julho 1990; Edital no 2342/28 de novembro 1990). Nesse mesmo ano, foi realizado o Primeiro Seminário sobre Análise de Viabilidade Populacional em Belo Horizonte, com a colaboração da IUCN. Em 1991, foi criado o Fundo Brasileiro de Micos-Leões, órgão que passou a arrecadar recursos para a preservação das quatro espécies de micos (RYLANDS, 1993).

Karen Strier deu prosseguimento às pesquisas com os muriquis na Reserva Particular do Património Natural (RPPN) Feliciano Miguel Abdala, criada em 2001. A pesquisadora, juntamente com uma equipe, é responsável pelo único trabalho de campo contínuo e prolongado com a espécie, totalizando 31 anos. O seu trabalho revelou dados surpreendentes sobre o maior e mais pacífico primata das Américas e pode ser considerado um projeto de sucesso, tanto pelo conhecimento adquirido ao longo das pesquisas, como também pelo aumento de aproximadamente $100 \%$ dos indivíduos do grupo original (QUAMMEN, 2008).

A muçuan, apesar de continuar a ser consumida em forma de "casquinha de muçuan" em alguns estados da região da Amazônia brasileira, foi classificada, em 2012, como pouco preocupante para conservação na nova Avaliação Científica do Risco de Extinção da Fauna Brasileira. Provavelmente porque o seu habitat tem sido alvo de projetos de conservação de outros quelônios ameaçados, principalmente da família Podocnemididae (http://www.tartarugasdaamazonia.org.br/index.php?option=com_content\&view=article\&i $\mathrm{d}=32 \&$ Itemid $=38$ ). 
As avoantes também se encontram protegidas, sob os cuidados do Centro Nacional de Pesquisa e Conservação de Aves Silvestres (Cemave), que realizou o anilhamento de 730 pássaros em 2013. Os ninhais, localizados no encontro dos estados do Ceará, Pernambuco e Piauí, formam os maiores pombais registrados para estudos da espécie com mais de 1 milhão de aves adultas (www.icmbio.gov.br/portal/index.php?option=com content \&view=article\&id=4133\&/temid= 17).

Paralelamente aos projetos já existentes, iniciados pela $\mathrm{FBCN}$ em parceria com o IBDF, a SEMA e com ONGs internacionais, novos projetos surgiram. Eles tiveram de incorporar novas demandas e de lidar com um contexto mais complexo e mais conflituoso. Com a afirmação da retórica do desenvolvimento sustentável, sobretudo a partir do relatório da Comissão Mundial sobre Meio Ambiente e Desenvolvimento, Nosso Futuro Comum, publicado em 1987, e da realização, em 1992, da Conferência das Nações Unidas sobre Meio Ambiente e Desenvolvimento, ganhou força o viés socioambientalista, que busca conciliar desenvolvimento econômico, conservação ambiental e combate à pobreza. No Brasil, isso levou a um contexto de tensões entre concepções preservacionistas/conservacionistas, herdeiras de uma tradição baseada nas preocupações com a proteção de espécies e de ecossistemas, e concepções socioambientalistas (FRANCO e SCHITTINI, 2010).

O conflito se intensificou durante o longo processo, 1992 a 2000, de tramitação do projeto de lei que originou o Sistema Nacional de Unidades de Conservação (SNUC-Lei no 9985/julho de 2000). A principal discordância se deu no que dizia respeito à permanência ou não de populações humanas dentro das unidades de conservação. O resultado foi a exclusão do SNUC da reserva legal e das áreas de preservação permanentes, que continuaram a ser regidas pelo código florestal de 1965, e das Terras Indígenas. Foram estabelecidos dois grandes grupos de unidades de conservação: proteção integral, que não permite populações humanas residentes, uso sustentável, que admite populações humanas residentes (FRANCO e SCHITTINI, 2010).

Simultaneamente à ampliação das ONGs ligadas ao socioambientalismo, algumas ONGs internacionais sediaram-se no Brasil e desvincularam as suas ações da $\mathrm{FBCN}$, como a $\mathrm{Cl}$ e a TNC, em 1988, e o WWF, em 1996. Paralelamente a esse processo, ONGs brasileiras de viés preservacionista-conservacionista, como a Funatura, fundada em 1986, e a Biodiversitas, 
fundada em 1989, ganharam autonomia em relação à $F B C N$. Como consequência, a FBCN foi gradativamente perdendo financiamento internacional e nacional e diminuindo suas atividades e representatividade no cenário dos projetos de conservação de espécies da fauna no Brasil (FRANCO e SCHITTINI, 2010).

Alguns dos novos projetos de conservação da fauna incluíram, como resposta às demandas dos movimentos socioambientais, as comunidades locais em suas ações, ora em atividades turísticas, ora como funcionários. A intensificação da educação ambiental ocorreu juntamente com esse processo. Em alguns projetos como o Tamar, o turismo e as atividades de educação ambiental já estavam presentes desde a fundação. Atualmente, cerca de 1200 pessoas de comunidades locais, em 21 bases de trabalho, distribuídas em mais de 1100 quilômetros da costa brasileira, trabalham de forma direta ou indireta com a conservação das tartarugas marinhas (FUNDAÇÃO PRO-TAMAR, 2010).

A estratégia de agregar a comunidade local também foi usada pelo Instituto de Estudos Socioambientais do Sul da Bahia (IESB), fundado em 1994. Nesse mesmo ano, formulou-se uma política de "entrega" da tutela do mico-leão-da-cara-dourada para a população local dos arredores da reserva Biológica do Una, no Sul da Bahia. O programa Brasil da $\mathrm{Cl}$, em parceria com Russell Mittermeier, também em 1994, iniciou um projeto para promover alternativas econômicas ao desmatamento causado pelas plantações de cacau. 0 envolvimento das populações residentes tinha como objetivo promover alternativas contra a destruição de habitats, a caça predatória e o tráfico de animais silvestres (KLEIMAN e RYLANDS, 2008).

Outros projetos surgiram com a educação ambiental como forma de sensibilização, geralmente focando crianças e adolescentes. Entre eles, o Projeto Grandes Felinos do Parque Nacional do Iguaçu, que recebeu, de 1990 a 2005, 4581 estudantes em sua sede o Projeto Salvando Anfíbios e a Floresta Atlântica, que recebeu, entre 1990 e 2004, dez mil e seiscentos alunos e mil e seiscentos visitantes independentes nas trilhas interpretativas e na sede localizada na borda da Serra Catarinense; o projeto Ecologia e Conservação do tubarão cabeça-de-cesto no arquipélago de Fernando de Noronha, que desde 2002 treina professores da rede pública do arquipélago e oferece oficinas para jovens entre oito e 25 anos (FUNDAÇÃO O BOTICÁRIO DE PROTEÇÃO À NATUREZA, 2005). 
O Instituto de Pesquisas Ecológicas (IPÊ), fundado em 1992, por Cláudio Pádua, administrador e ecólogo, e por sua esposa Suzana Pádua, educadora ambiental, é um modelo de ação integrada, incluindo pesquisa sobre espécies ameaçadas, educação ambiental, restauração de habitats, envolvimento comunitário e atuação para a elaboração de políticas públicas ambientais. A geração de renda com o objetivo de diminuir a pressão das famílias sobre a biodiversidade, no entorno e dentro das áreas de atuação do IPÊ é prioridade dos projetos. Dentre as espécies manejadas pelo IPÊ estão o mico-leão-preto; o mico-leão-dacara-preta; a avifauna da região do Pontal do Paranapanema, SP; a onça-parda (Puma concolor), a onça-pintada (Panthera onca) e a jaguatirica (Leopardus pardalis), que fazem parte do projeto detetives ecológicos; e a anta (Tapirus terrestris) do Parque Estadual Morro do Diabo, bem como dos remanescentes florestais do Pontal do Paranapanema. Os projetos para a fauna buscam conciliar o desenvolvimento da região com a conservação da Natureza, incentivando o estabelecimento de corredores florestais, de agroflorestas e de trampolins de biodiversidade (www.ipe.org.br/ipe-instituto-de-pesquisas-ecologicas; Côrrea, 2006).

A gestão de áreas protegidas com o envolvimento das populações residentes ou do entorno de áreas protegidas, a partir da década de 1990, tornou-se alvo de vários programas de financiamento para a conservação da biodiversidade do Banco Mundial por intermédio do "Global Environmental Fund" (GEF). As grandes ONGs internacionais também têm apostado na conciliação entre conservação e uso sustentável. O WWF, por exemplo, em 1995, investiu quase 8 milhões de francos suíços em projetos que visavam o desenvolvimento sustentável e a conservação baseada na comunidade e 0,2 milhões para proteger espécies, objetivo principal de atuação desde a sua fundação (Dourojeanni, Pádua, 2001).

O Projeto Mamirauá é um exemplo significativo de conservação da biodiversidade em parceria com as populações locais, baseado na restrição de acesso aos recursos naturais de acordo com decisões tomadas por partes interessadas. Fruto de arranjos políticosinstitucionais nacionais e internacionais, que resultaram na criação de uma nova categoria de unidade de conservação, a Reserva de Desenvolvimento Sustentável. Um longo processo iniciado, em 1984, pelo biólogo José Márcio Ayres e pelo fotógrafo Luis Cláudio Marigo, com o objetivo inicial de preservar o uacari-branco (Cacajao calvus calvus) e o macaco-de-cheirode-cabeça-preta (Saimiri vanzolinii), espécies de primatas endêmicas da região, deu origem à Reserva de Desenvolvimento Sustentável do Mamirauá - RDSM (INOUE, 2007). 
Em 1987, durante a gestão de Paulo Nogueira Neto na SEMA, a Estação Ecológica Mamirauá (EEM) foi criada, porém nunca foi implantada como unidade de conservação federal. Em 1990 (decreto n 12.836, de 9 de março de 1990), foi estabelecida a EEM pelo governo do Estado do Amazonas como uma unidade de conservação estadual. As relações entre Ayres com pessoas influentes envolvidas com a conservação foram essenciais, sobretudo com os primatólogos Russel Mittermeier, da $\mathrm{Cl}$, que em um artigo publicado em 1977 apontou a região do lago do Mamirauá como única área de distribuição dos uacarisbrancos, John Robison, da "Wildlife Conservation" (WCS), e Kent Redford da TNC (INOUE, 2007).

Devido à presença de pessoas residentes na área destinada à EEM e ao desejo de pesquisadores, cujo núcleo central era a primatologia, de preservar a biodiversidade da região, a ideia da criação de um novo modelo de unidade de conservação foi se configurando. A EEM deu lugar à RDSM em 1996 (Lei n 2.411, do Estado do Amazonas). Atualmente, a rede de relações do Projeto Mamirauá, coordenada por pesquisadores e pela Sociedade Civil Mamirauá, envolve o "Departament for international Development" (DFID), da Inglaterra, a WCS, a $\mathrm{Cl}$ e o WWF, o Governo do Amazonas, o CNPQp/Ministério da Ciência Tecnologia e Inovação, o Fundo Amazônia e Comunidades locais da região. O processo de criação, cooperação internacional e estabelecimento da RDSM teve como espécies guarda-chuva o uacari-branco e o macaco-de-cheiro-de-cabeça-preta, e hoje o Instituto Mamirauá promove a pesquisa, o monitoramento e a preservação de várias outras espécies.

Projetos como o IPÊ e o Mamirauá são modelos de sucesso no que diz respeito à conciliação entre conservação da biodiversidade e uso sustentável de recursos naturais. Eles fomentam tomadas de decisão de forma coletiva, envolvendo moradores, pesquisadores, gestores de unidades de conservação, patrocinadores e membros de instituições do Estado, mas por outro lado enfrentam muitos desafios (DOUROJEANNI e PÁDUA, 2001).

Após quarenta e seis anos de fundação dos primeiros projetos para a preservação do mico-leão-dourado e dos muriquis, e embora tenha havido sucesso em salvá-los da extinção, eles continuam entre os primatas mais ameaçados do novo mundo. Isto dificilmente será alterado, já que a Mata Atlântica, habitat exclusivo dessas espécies, tem sua área restrita a aproximadamente 7\% do território de sua ocorrência original (DEAN, 1996). Juntamente com 
os dois primatas estão 1173 espécies da fauna ameaçadas de extinção presentes na última versão da lista da fauna brasileira ameaçada de extinção (MMA, 2014).

Vítimas, sobretudo, da destruição de habitats, as espécies da fauna brasileira ilustram o problema mais amplo da perda acelerada da biodiversidade. Os projetos de conservação da fauna, com maior ou menor participação de comunidades locais, têm um papel urgente a ser desempenhado no esforço de diminuir a intensidade da crise global de extinção de espécies em curso.

\section{Conclusão}

Apesar dos dados alarmantes, sem os projetos de conservação da fauna, a situação das espécies ameaçadas seria muito pior. Os projetos aqui tratados são exemplos bemsucedidos e duradouros no campo da biologia da conservação e da educação ambiental. Eles enfocam a parte mais visível do problema das extinções, as espécies carismáticas, aquelas que despertam a simpatia e apelam mais fortemente aos sentimentos dos humanos. Essas espécies, no entanto, não são apenas carismáticas, elas são indicadoras da saúde dos ecossistemas e atuam como espécies guarda-chuva. Elas podem e devem contribuir para o desenvolvimento de uma consciência mais ampla em relação à biodiversidade, que permita compreender o seu valor para garantir os serviços ambientais dos quais a humanidade depende, mas que também desperte os humanos para uma ética mais abrangente, capaz de atribuir valor intrínseco à diversidade de formas de vida que habita o planeta.

Experiências de conservação da fauna têm valor educativo e simbólico, contribuem, não só para o debate em torno da sustentabilidade no seu caráter mais amplo, como também enfatizam a questão da interdependência entre os seres humanos e os outros seres vivos. Os vários significados atribuídos e o convívio com os animais têm sido elementos constitutivos das mais variadas culturas humanas. Sem animais, a história humana seria muito mais pobre e o futuro, como se poderá descobrir um dia, muito mais curto.

\section{REFERÊNCIAS BIBLIOGRÁFICAS}

BRIDGWATER, Donald D. (ed.) Saving the lion marmoset. Wheeling, WV: Wild Animal Propagation Trust. 1972.

CANDISANI, Luciano. Muriqui, uma jornada fotográfica pelas florestas do maior macaco das Américas. São Paulo: DBA ArtesGráficas. 2004. 
CARVALHO, José Cândido de Melo. Algumas Reminiscências Conservacionistas. In: Boletim FBCN, no 23, Rio de Janeiro, ano 1988. p. 125.

CHAN, K. M. A. et al. Opinion: Why protect nature? Rethinking values and the environment. Proceedings of the National Academy of Sciences, v. 113, n. 6, p. 1462-1465, 2016.

COIMBRA-FILHO, Adelmar; MITTERMEIER, Russel. Conservation of the Brazilian lion tamarins (Leonthopitecus rosalia). In: Primate Conservation, p. 59-94. New York: Academic Press. 1977.

Hybridization in the genus Leontopithecus, L. r. rosalia (Linnaeus, 1766), L. r. chrysomelas (Kuhl, 1820) (Callitrichidae, Primates). Revista Brasileira de Biologia. v.36, p.129-137. 1976.

CORRÊA, Marcos Sá. Água mole em pedra dura: dez histórias da luta pelo meio ambiente. Rio de Janeiro: Aeroplano. 2006.

DEAN, Warren. A ferro e fogo: história da devastação da Mata Atlântica brasileira. São Paulo: Companhia das Letras. 1996.

DIAMOND, Jared. Armas, Germes e Aço, os destinos das sociedades humanas. Record. 1997.

DORST, Jean. Antes que a natureza morra: por uma ecologia política. São Paulo: Edgard Blucher. 1973.

DOUROJEANNI, Marc J.; PÁDUA, Maria Tereza Jorge. Biodiversidade: a hora decisiva. Curitiba: Fundação O Boticário/UFPR. 2001.

DUARTE, Regina Horta. Birds and Scientists in Brazil: In Search of Protection, 1894-1938. In: Few, Martha; Tortorici, Zeb (editors). Centering Animals in Latin American History. The United States of America: Duke University Press, p.270-301.2013.

DUMOND, Frank V. Comments on minimum requirements in the husbandry of the golden marmoset Leontideus rosalia. Laboratory Primate Newsletter v.I0, p.30-37. 1972.

FBCN, Boletim Informativo no 1, Rio de Janeiro.1966.

FBCN, Boletim Informativo no 2, Rio de Janeiro. 1967.

FBCN, Boletim Informativo no 4, Rio de Janeiro. 1969.

FBCN, Boletim Informativo no 8, Rio de Janeiro. 1973.

FBCN, Boletim Informativo no 8, Rio de Janeiro. 1973.

FBCN, Boletim Informativo no 7, Rio de Janeiro. 1972.

FBCN, Boletim Informativo no 9, Rio de Janeiro. 1974.

FBCN, Boletim Informativo no 23, Rio de Janeiro. 1988.

FRANCO, José Luiz de Andrade; DRUMMOND, José Augusto. Nature Protection: the FBCN and Conservation Initiatives in Brazil, 1958-1992. Historia Ambiental Latinoamericana y Caribeña HALAC. Belo Horizonte, v. II, n. 2, p. 338-367. 2013. 
FRANCO, José Luiz de Andrade; SCHITTINI, Gilberto. História das Áreas Protegidas: Objetivos e Justificativas para a Proteção da Natureza. In: Gandara, Gercinair Silvério. (Org.). Rios e Cidades: Olhares da História e Meio Ambiente. Goiânia: PUC, p. 203-227. 2010.

FRANCO, José Luiz de Andrade; DRUMMOND, José Augusto. História das preocupações com o mundo natural no Brasil: da proteção à natureza à conservação da biodiversidade. In: Franco, José Luiz de Andrade; Silva, Sandro Dutra; Drummond, José Augusto; e Tavares, Giovana Galvão (Orgs.). História Ambiental: fronteiras, recursos naturais e conservação da natureza. Rio de Janeiro: Garamond, pp. 333-366. 2012.

FUNDAÇÃO O BOTICÁRIO DE PROTEÇÃO À NATUREZA. Sinais da Vida: Algumas histórias de quem cuida da natureza no Brasil. São Paulo: Fundação o Boticário de Proteção à Natureza. 2005.

FUNDAÇÃO PRÓ-TAMAR, Assim nasceu o Projeto TAMAR. Salvador, BA: 2000.

GROOM, Martha J.; MEFFE, Gary K.; CARROLL, C. Ronald (Eds.). Principles of Conservation Biology. Massachusetts: Sinauer Associates, (third edition). 2006.

HOLDGATE, Martin. The green web: a union for world conservation. Routledge, 2014.

FERNANDEZ, Fernando. A.S; ARAUJO, Bernardo, B.A. As primeiras fronteiras: impactos ecológicos da expansão humana pelo mundo. In: Franco,José Luiz de Andrade; Silva, Sandro Dutra; Drummond, José Augusto; Tavares, Giovana Galvão. (Org.). História Ambiental: Fronteiras, Recursos Naturais e Proteção da Natureza. 1ed. Rio de Janeiro: Garamond, p. 97-117. 2012.

INOUE, Cristina Yumie Aoki. Regime global de biodiversidade: o caso Mamirauá. Brasília: Editora Universidade de Brasília. 2007.

KLEIMAN, Devra G.; RYLANDS, Anthony B. (Editores) Micos Leões: biologia e conservação. Brasília: MMA. 2008.

MAGNANINI, Alceo. Conceitos de Conservação. Boletim Informativo $F B C N$, no 1, Rio de Janeiro. p.15.1966.p.15.

MAGNANINI, Alceo. Progress in the development of Poço das Antas Biological Reserve for Leontopithecus rosalia rosalia in Brazil. In: Kleiman, Devra.(ed.) The Biology and Conservation of the Callitrichidae. p. 131-136.Washington: Smithsonian Institution Press. 1978.

MAGNANINI, Alceo; COIMBRA-FILHO, Aldemar. The establishment of a captive breeding program and wildlife research center for the lion marmoset, Leontopithecus, in Brazil. In: Bridgwater, D. (ed) Saving the Lion Marmosets, p. 110-119. Wheeling, Wildlife Propagation Trust. 1972.

MAYR, Ernst. Biologia, Ciência Única. São Paulo: Cia das Letras, 2005.

MCCORMICK, John. Rumo ao Paraíso: A História do Movimento Ambientalista. Rio de Janeiro: RelumeDumará, 1992.

MENDES, Sérgio Lucena; SILVA, Mariana Petri da; STRIER, Karen B. O muriqui. Vitória: Instituto de Pesquisas da Mata Atlântica. 2010.

MITTERMEIER, Russel; COIMBRA-FILHO, Aldemar. Conservation of eastern Brazilian primates. Relatório não publicado. 1981.In; Kleiman, Derva. Mico-Leões. Brasília: MMA, 2008. 
MMA. Ministério do Meio Ambiente. Espécies da fauna brasileira ameaçadas de extinção. Portarias no. 444 e 445, de 17 de dezembro de 2014, publicada no Diário Oficial da União n 245, de 17 de dezembro de 2014. 28 de maio de 2003. Seção 1. p. 121-126. 2014.

NASH, Roderick. Wilderness and the American Mind. Yale: Yale University Press, 2001.

PRIMACK, Richard; RODRIGUES, Efraim. Biologia da Conservação. Londrina: E. Rodrigues. 2001.

QUAMMEN, David. O canto do dodô: Biogeografia de Ilhas Numa Era de Extinções. Rio de Janeiro: Companhia das Letras. 2008.

RYLANDS, Anthony .B.(ed) Marmosets and tamarins: Sytematics, behaviour, and ecology, p. 11-77. Oxford: Oxford University Press. 1993.

VUURE, T. van. History, morphology and ecology of the Aurochs (Bos primigenius). Disponível em: http://members.chello.nl/ t.vanvuure/oeros/uk/lutra.pdf. 2002.

URBAN, Teresa. Saudade do Matão: Relembrando a História do Conservacionismo no Brasil. Curitiba: UFPR/Fundação O Boticário/ Mac Arthur Foundation. 1998.p.116.

WIED-NEUWIED, Maximiliano. Viagem ao Brasil nos anos 1815 a 1817. Disponível em http://www.brasiliana.com.br/obras/viagem-ao-brasil-nos-anos-de-1815-a-1817/. 1940.

WILSON, Edward O. Diversidade da Vida. São Paulo: Cia das Letras. 1994. 